\title{
O MERCADO DA CARNE BOVINA NO BRASIL
}

\author{
The market of the Brazilian cattle flesh
}

\section{Felipe Pohl Souza}

Médico Veterinário, Mestreem Ciências Veterinárias, Professoradjunto I daPontifícia UniversidadeCatólica do Paraná, Curitiba, PR - Brasil, e-mail: felipe.pohl@ pucpr.br

\section{Resumo}

0 presente tema objetiva dar uma visão do mercado da carne no Brasil, estabelecendo algumas relações com o mercado externo desta commodity. Coloca-se em evidência a evolução das exportações brasileiras de carne bovina para o mundo globalizado, tomando-se como base a produção de carne com baixos custos. Alguns obstáculos, contudo são destacados, contracenando-se a aquilo que poderia parecer uma situação tranquila à exportação. A sanidade destaca-se como um dos grandes entraves. Contudo, os países compradores exigem um sério processo da rastreabilidade além da exigência da qualidade do produto adquirido. Além desses aspectos, alguns países fazem várias exigências em função da não agressão ao meio ambiente, referindo-se principalmenteà FlorestaAmazônica. O Brasil tem enfrentado dura concorrência de outros países exportadores, os quais podem produzir carne a um baixo custo, destacando a Índia e os países do leste europeu, que estão se organizando e têm a vantagem da proximidade do mercado consumidor. Contudo, o Brasil permanece como um grande potencial para os negócios com a carne bovina. Exige-se dos produtores dessa commodity uma exemplar organização, de modo a equacionar as questões sanitárias, ambientais e estratégicas.

Palavras-chave: Carne bovina; Mercado; Brasil; Exportação.

\begin{abstract}
The aim this review is to give an overall view about the market-flesh in Brazil and in the world. An economic analysis about the Brazilian flesh-exportation and evolution is done. Several problems are explained. The health condition is the major commercial difficulty. The rastreability and the quality of the Brazilian flesh are required too, besides of no-aggression against the environment, mainly with respect to the Amazon Forest. Brazil had a hard concurrence from other countries, mainly India and the East European Countries. However Brazil remains with a great potential to the flesh business in the world. This depends mainly of the union of Brazilian flesh producers, to improve the questions like sanitary aspect, environment and other strategies.
\end{abstract}

Keywords: Bovine flesh; Market; Brazil; Exportation. 


\section{INTRODUÇÃO}

No final do século XVIII, a carne bovina e o couro eram importantes produtos de exportação, sendo responsáveis pelo grande desenvolvimento do Rio Grande do Sul, que abastecia o Sudeste e 0 Nordeste brasileiro, e também alguns países da América Central. No ano de 1797, a capitania do Rio Grande do Sul, já exportava 13 mil arrobas de charque (BRASIL ESCOLA, 2007)

Três séculos depois, a pecuária nacional vive novo ciclo da carne bovina, principalmente com a conquista do mercado internacional, tornando o Brasil o maior exportador do mundo. Essa participação no mercado internacional teve início em 2001, sendo que em 2003 o valor das exportações ultrapassou a casa do bilhão de dólares com mais de um milhão de toneladas do produto sendo exportada, conforme se pode observar na Figura 1.

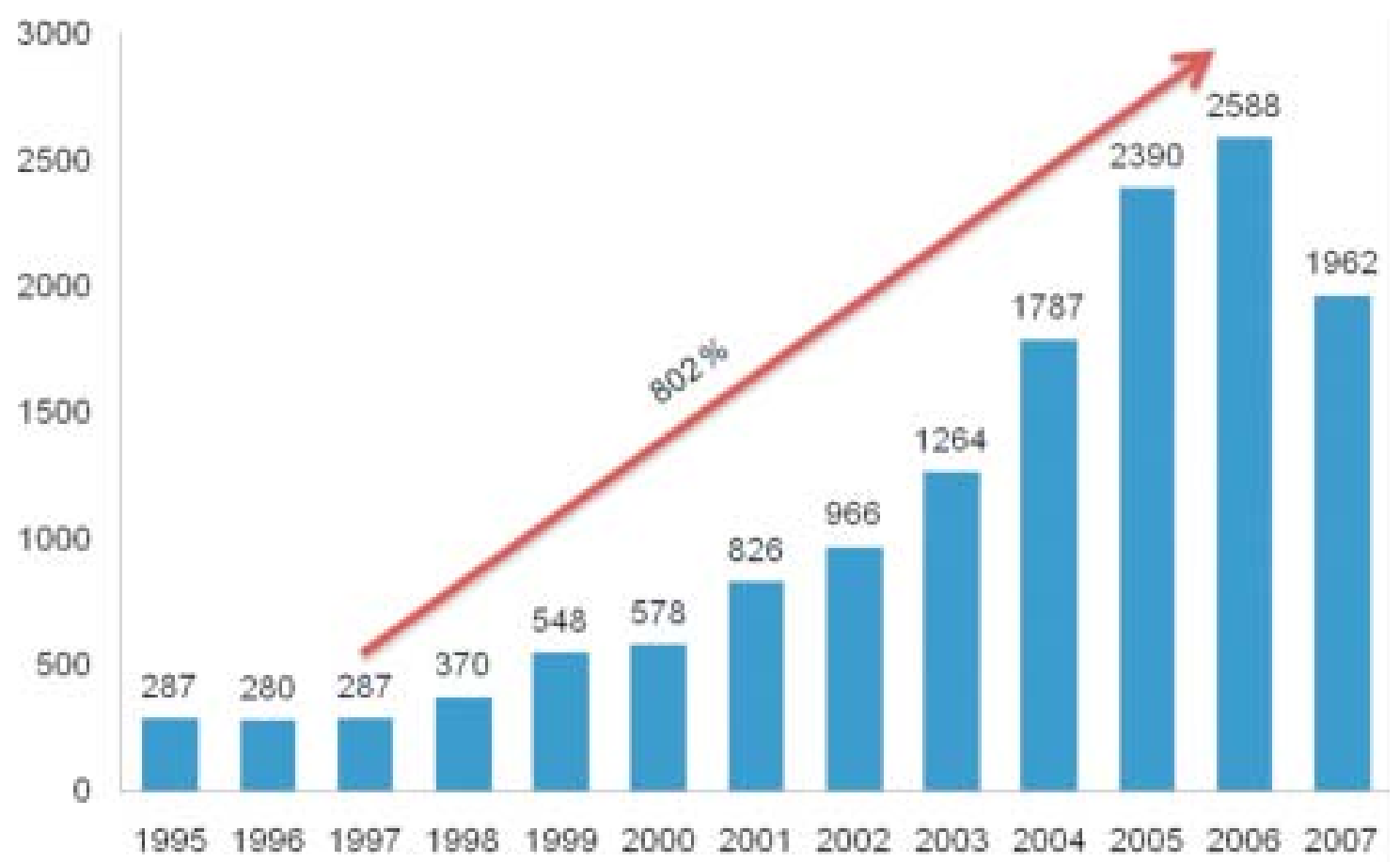

FIGURA 1 - Evolução das exportações brasileiras de carne de 1995 a 2007

Figure 1 - E volution of the Brazilian cattle flesh ex port from 1995 to 2007

*2007 até setembro

Fonte: ABIEC, 2007.

Esse aumento expressivo deveu-se a problemas dos tradicionais fornecedores internacionais. $\mathrm{Na}$ Figura 2 pode-se observar os principais exportadores no ano de 2000 e 2005, verificando-se 0 incremento da participação do Brasil, ao duplicar suas exportações em cinco anos; pode-se ainda observar a significativa retração dos E stados Unidos e da Comunidade Europeia, que na figura aparece como outros. 

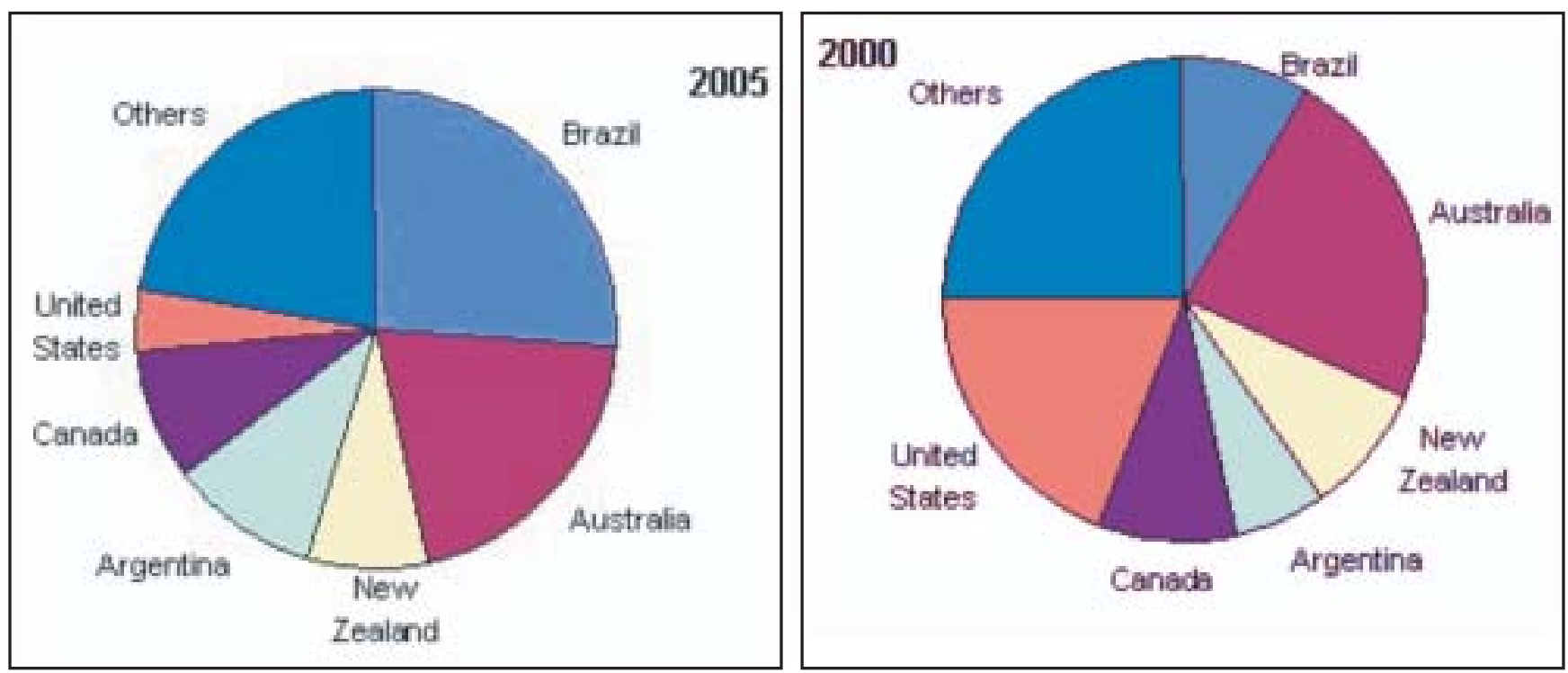

FIGURA 2 - Retração das exportações americanas e europeias em função da encefalopatia espongiforme bovina EEB (vaca louca) e febre aftosa, respectivamente, diagnosticados em 2003 e 2005

Figure 2 - A merican and E uropean ex ports retraction due to encephalopathy spongiform bovine and aftosa fever respectively, in 2003 and 2005

Fonte: ABIEC, 2007.

A diminuição da participação americana deveu-se aos casos de encefalopatia espongiforme bovina - EEB (vaca louca), diagnosticados em 2003 e 2005, enquanto a Argentina e a Inglaterra tiveram problemas com febre aftosa.

Esses eventos sanitários, mais o aumento da demanda mundial, pela elevação da renda nos países emergentes, colocaram o Brasil na posição que ocupa hoje. 0 Brasil não estava plenamente preparado para esse aumento, mas a indústria da carne conseguiu rapidamente adequar-se aos novos tempos e vem ocupando todos os espaços possíveis no mercado mundial. Por outro lado, os produtores ainda estão se adaptando aos novos tempos.

Atualmente, o Brasil exporta para mais de 150 países, mas não atingiu os compradores mais exigentes e, consequentemente, os que melhor remuneram o produto, como é o caso do Japão e da Coreia, são atendidos pela Austrália e N ova Zelândia, países tradicionais pela excelência do produto (ABIEC, 2007).

A indústria frigorífica brasileira tem tratado a carne bovina como uma "commodity", onde o importante é o volume de venda com preço baixo e margem pequena de lucro. Essa posição está mudando o cenário da pecuária nacional, que está se adaptando a essa nova realidade. Um exemplo disso são os grandes projetos de confinamento que estão surgindo no Centro-O este brasileiro.

A derrubada das altas taxas inflacionárias impostas pelo "Plano Real", a partir de 1994, deu início às grandes modificações no setor primário brasileiro, particularmente na atividade pecuária, que por muito tempo obteve seus lucros pela elevada desvalorização da moeda. Esse novo momento exigiu que as propriedades rurais se tornassem empresas eficientes, o que fez com que os índices produtivos se elevassem consideravelmente. Não se pode perder de vista que, mesmo as pequenas modificações em índices produtivos, representam um acréscimo considerável de animais e carne no mercado, em consequência do tamanho do rebanho brasileiro. Felizmente para os produtores, esse aumento de produção coincidiu com 0 aumento das exportações, que hoje são responsáveis pelo consumo de aproximadamente $25 \%$ da produção nacional. Isso demonstra a importância dos negócios internacionais para a manutenção dos preços do boi e da carne no Brasil, pois, se este volume, que hoje é exportado, ficasse no mercado interno ter-se-ia uma queda significativa dos preços, pelo excesso de oferta, 
considerando que a população não tem renda para aumentar o consumo, muito além dos atuais 36 quilos "per capita". Portanto, a participação do Brasil no mercado internacional é vital para que a pecuária continue sendo uma atividade viável.

O cenário internacional é propício para a pecuária brasileira, principalmente no que diz respeito às demandas internacionais. A entrada de novos consumidores como a Rússia e a China, assim como melhoria da economia de países emergentes da África e Ásia, determinaram maior demanda por carne bovina, demanda esta que está sendo atendida principalmente com a carne brasileira. O utra vantagem do Brasil é o enorme potencial de aumento de produtividade, seja pela melhoria da eficiência das áreas de pastagem já existentes ou pela abertura de novas áreas, algo em torno de 330 milhões de hectares, segundo dados do Ministério da Agricultura, Pecuária e Abastecimento - MAPA, 2007.

Observando-se apenas esses aspectos, tem-se a impressão de que o Brasil se apresenta atualmente com os mercados garantidos, mas a situação não é tão tranquila, pois alguns aspectos importantes devem ser considerados:

Sanidade. Esse talvez seja o maior entrave da pecuária brasileira, pois, apesar de alguns avanços, não se conseguiu ainda controlar de maneira eficiente a Febre Aftosa, doença que caracteriza subdesenvolvimento brasileiro nos aspectos de saúde animal. 0 programa de erradicação dessa doença no cone sul está saindo do papel, depois dos últimos focos no Mato G rosso do Sul e no Paraná. O Brasil terá que tomar a frente e provavelmente arcar com os maiores custos desse processo, pois é aqui que está o maior rebanho comercial do mundo e, também, as maiores perspectivas de lucro com a atividade pecuária. Não se pode esperar que países com rebanhos muito menores tomem essa iniciativa.

O utro entrave é a morosidade com que o Programa Nacional de Controle e Erradicação de Brucelose e Tuberculose - PNCEBT, 2007, do MAPA, está sendo implantado. Certamente, depois da febre aftosa, essas duas enfermidades serão as próximas exigências dos compradores internacionais, principalmente da Comunidade Europeia (CE). Esse programa foi um grande avanço nas relações entre iniciativa privada e os órgãos oficiais, permitindo uma divisão de responsabilidades, deixando a execução por conta dos veterinários privados e a regulamentação e fiscalização por conta dos veterinários oficiais. Mas, apesar dessa nova perspectiva, o programa não conseguiu a adesão nem dos produtores nem dos médicos veterinários, o que é lamentável.

Esses são apenas alguns exemplos das dificuldades que ainda se tem para contornar os aspectos sanitários, para se poder garantir produtos seguros para nossos clientes e se conseguir conquistar mercados mais exigentes e melhores pagadores.

Rastreabilidade. D epois da ocorrência dos casos de vaca louca na Inglaterra e sua provável relação com a D oença de Creutzfeld-Jakob Variante, que foi responsável por aproximadamente 150 óbitos humanos, principalmente na Europa, uma preocupação surgiu, a de que é necessário rastrear os animais e os produtos para poder controlar e prevenir problemas como esse. Assim, o Regulamento (CE) 1760/ 2000 lançou as bases para o sistema de rastreabilidade e rotulagem de carne na União E uropeia, que obrigou a todos os Estados Membros da CE a criarem seus sistemas de identificação e registro de bovinos. Os negócios internacionais são arbitrados pela O rganização Internacional do Comércio $\mathrm{OMC}$, permitindo que um país exija de seus fornecedores os mesmos padrões que adota internamente (conhecido como reciprocidade); sendo assim, o Brasil foi obrigado a implantar em 2002 o seu programa de rastreabilidade, para que pudesse continuar exportando para os Países membros da CE. O SISBOV (Serviço de Rastreabilidade da Cadeia Produtiva de Bovinos e Bubalinos) foi implantado pela Instrução Normativa (IN) no 1 de 9 de janeiro de 2002, estabelecendo uma meta extremamente ousada, qual seja, todo o rebanho nacional rastreado até 2007. Essa IN foi revogada pela IN no 1 de 21 de janeiro de 2005, pela impossibilidade de cumprimento e pelas dificuldades encontradas. Mas a meta inicial provavelmente foi uma das causas do fracasso do SISBO V. Uma nova IN, no 17 de 13 de julho de 2006 fez mais algumas modificações, mas, ainda assim, o sistema mostrou-se falho e não foi assimilado pelos pecuaristas e técnicos. O sistema só funcionará quando os produtores compreenderem que a rastreabilidade é um importante instrumento gerencial e, portanto, deve ser feito em todos os animais desde o nascimento 
até 0 abate. 0 gerenciamento das informações será um grande instrumento de avaliação de rebanhos e propriedades. Nosso sistema de rastreabilidade tem sido questionado, particularmente pelos pecuaristas irlandeses, que são os mais prejudicados pela concorrência da carne brasileira. Uma missão não oficial da CE , realizada no primeiro semestre de 2007, levantou uma série de falhas, principalmente no controle do transporte de animais. Essas falhas foram comprovadas por uma missão de técnicos da CE, em novembro de 2007. Esses problemas culminaram com a "crise" no início de 2008, onde o CE exigiu do MAPA, uma relação de 300 propriedades aptas a exportar, que depois de muitas idas e vindas ficou restrita a 86 fazendas. Essa situação demonstra a importância da adoção de um programa sério e eficiente de rastreabilidade brasileira (MUSTEFAGA, 2006).

Qualidade de produto. Esse é um item bastante polêmico, mas as exportações brasileiras não atingiram os países mais exigentes e ainda não se conseguiu atingir o chamado HORECA (hotéis, restaurantes e cantinas), dentro da Europa. Esse segmento de mercado, que paga preços mais elevados, exige qualidade de produto, sendo a Argentina o grande fornecedor desse segmento na América do Sul. Portanto, tem-se ainda um grande trabalho para se poder colocar a carne brasileira nesses seletos nichos de mercado.

Integração da Cadeia. Um dos grandes problemas da bovinocultura de corte brasileira é que não há uma relação de confiança entre as partes, principalmente entre os pecuaristas e a indústria. Essa falta de confiança não permite o estabelecimento de compromissos com qualidade, volume e constância do produto, que é fundamental, principalmente para fidelização de clientes e criação de marcas.

Valor de venda. 0 Brasil se tornou o maior exportador de carne bovina do mundo, porque tem um produto barato e este é o grande trunfo dos exportadores para conquista de novos mercados, tornando-se uma "commodity", o que fez com que alguns grupos de frigoríficos se tornassem verdadeiros conglomerados, sendo muitos já com atuação internacional. Isso dificulta ainda mais a relação entre as grandes indústrias e os produtores, exigindo cada vez mais que se busque produzir grandes volumes a custos baixos, com uma lucratividade por cabeça cada vez menor. A Figura 3 mostra a evolução dos preços desde a década de 70, onde se pode entender a correlação entre 0 aumento de produção e a redução dos valores da arroba.

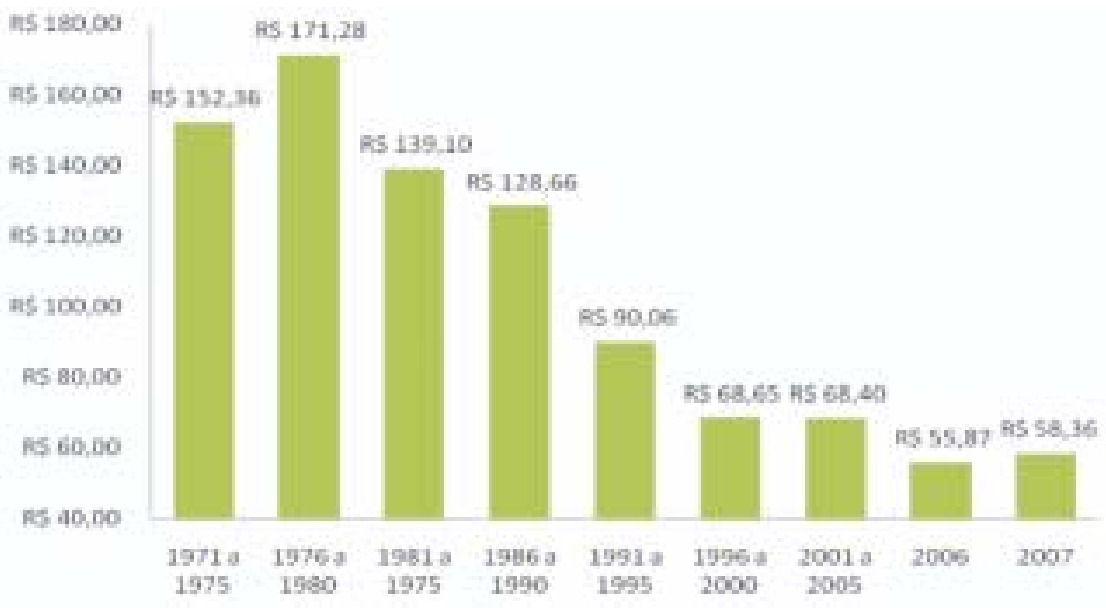

FIGURA 3 - Evolução de preços por arroba 1970 a 2006, deflacionados pelo IG P-D I (FGV)

Figure 3 - Prices evolution from 1970 to 2006, deflation made by IG P-D I (F G V )

Fonte: VILA et al., 2007. 
Meio ambiente. Esse é outro assunto bastante polêmico, pois o Brasil tem sido sistematicamente acusado, particularmente pelos irlandeses, de produzir carne às custas da destruição da floresta amazônica e, consequentemente, de ser responsável pelas queimadas e, por extensão, pelo efeito estufa. Infelizmente essa afirmação não é incorreta pois, com a diminuição do resultado financeiro por cabeça, há a necessidade de volumes cada vez maiores, determinando a abertura de novas fronteiras pecuárias. Sendo economicamente inviável utilizar-se de terras de agricultura para a pecuária, novas áreas estão sendo abertas na região Norte, para o estabelecimento de projetos economicamente sustentáveis. Portanto, esse é um ponto que deve ser observado e discutido. Talvez haja a necessidade de se impor um limite na ocupação da A mazônia e exigir das propriedades certificação de responsabilidade ambiental. D eve-se igualmente trabalhar na recuperação das áreas degradadas, aumentando seu potencial de produção e diminuindo a necessidade de desmatamento. 0 utro ponto importante é mostrar que boa parte da produção de carne bovina brasileira é realizada em propriedades, que estão se adequando às obrigações ambientais, ou seja, mantendo as áreas de reserva legal, o que tem resultado em avanços significativos na preservação da biodiversidade.

Volume de produção. 0 Brasil está produzindo cada vez mais animais e, consequentemente, mais carne, acreditando que os mercados são infinitos, mas que talvez seja hora de uma boa avaliação do potencial dos mercados interno e internacional, para que um planejamento de crescimento controlado possa garantir preços razoáveis, tanto para os pecuaristas como para as indústrias, pois, como já foi comentado, existe dependência do mercado internacional e quanto mais for produzido, maior o risco de uma quebra de preços. A Figura 4 mostra o aumento vertiginoso da produção, que caso assim continue, pode não ter para onde ser escoada.

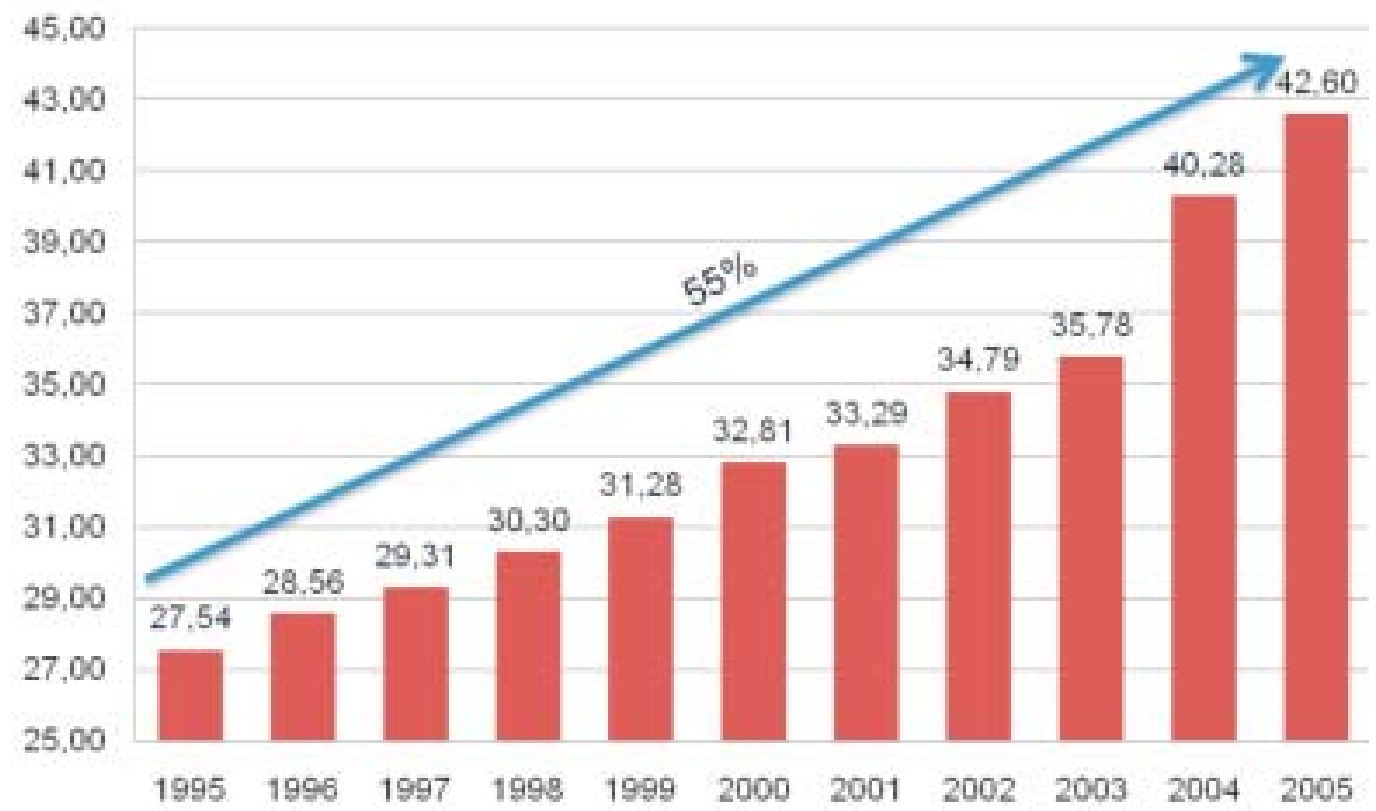

FIGURA 4 - Abates bovinos em milhões de cabeça

Figure 4 - Bovine slaughter (million)

Fonte: Scot Consultoria 2007. 
Concorrência. O Brasil tem uma situação realmente privilegiada no que diz respeito ao potencial e custos de produção, mas que não se pode imaginar que outros países não queiram participar deste mercado. Não são com os produtores tradicionais, com os quais deve haver a preocupação (Austrália, Nova Zelândia e Argentina), mesmo porque por hora não se tem colocado em risco as posições desses países, pois eles atuam em mercados inacessíveis para a carne brasileira. A preocupação procede dos países que possuem grandes rebanhos e potencial de produzir a custo baixo como a India, que nos últimos cinco anos teve um aumento de aproximadamente $80 \%$ no volume de exportação, ficando atrás apenas do Brasil e do Uruguai, conforme a Tabela 1. 0 produto indiano é de baixa qualidade, mas de custos pouco elevados, e que, portanto, é uma ameaça para a "commodity" carne bovina brasileira. O utra preocupação deve existir com os países do leste europeu, que estão se organizando para atender aos países da CE e tem a vantagem da proximidade.

TABELA 1 - Exportações mundiais de carne bovina (em mil toneladas equivalente carcaça)

Table 1 - W orld ex ports of bovine flesh (in thousands tons carcass)

\begin{tabular}{|c|c|c|c|c|c|c|c|}
\hline País & 2002 & 2003 & 2004 & 2005 & $2000^{*}$ & $2007^{* *}$ & Var. (2006/ 2002) \\
\hline Brasil $^{1}$ & 1.006 & 1.301 & 1.854 & 2.198 & 2.200 & 2.420 & $118,69 \%$ \\
\hline Austrália & 1.366 & 1.264 & 1.394 & 1.413 & 1.420 & 1.495 & $3,95 \%$ \\
\hline Índia ${ }^{2}$ & 417 & 439 & 499 & 627 & 750 & 800 & $79,86 \%$ \\
\hline Estados Unidos & 1.100 & 1.142 & 209 & 317 & 523 & 680 & $-52,88 \%$ \\
\hline Argentina & 348 & 386 & 623 & 762 & 500 & 600 & $43,68 \%$ \\
\hline Nova Zelândia & 486 & 558 & 606 & 589 & 540 & 570 & $11,11 \%$ \\
\hline Uruquai & 262 & 325 & 410 & 487 & 510 & 520 & $94,66 \%$ \\
\hline Canadá & 609 & 383 & 557 & 551 & 455 & 440 & $-25,29 \%$ \\
\hline União Européiia³ & 485 & 388 & 358 & 255 & 200 & 200 & $-58,76 \%$ \\
\hline Outros países & 310 & 279 & 212 & 224 & 153 & 164 & $-50,65 \%$ \\
\hline TOTAL & 6.399 & 6.465 & 6.722 & 7.423 & 7.251 & 7.889 & $13,31 \%$ \\
\hline
\end{tabular}

FONTE: USADA, (2006);

${ }^{1}$ Fórum Nacional Permanente de Pecuária de Corte;

Inclui búfalo;

${ }^{3} \mathrm{U} . \mathrm{E}-25$.

Previsão. Bem-Estar Animal. Esse é outro aspecto que vem criando barreiras aos produtos de origem animal, tornando os consumidores mais exigentes.

Pelo exposto, pode-se perceber que há um significativo potencial para os negócios da carne bovina no Brasil. Há igualmente muito a ser feito, para que a cadeia produtiva da carne bovina funcione de maneira eficiente e justa em todos os níveis. Provavelmente o ponto mais importante nesse contexto todo, seja a tomada de consciência brasileira dos pecuaristas, onde a exportação destaque-se como um ponto fundamental, para que haja a estabilidade da cadeia da carne bovina, objetivando o atendimento às exigências dos compradores. Isso se caracteriza como uma obrigação de todos os envolvidos. Se isso for compreendido as questões sanitárias, ambientais, estratégicas e de segurança alimentar, certamente serão equacionadas de maneira eficiente e todos se beneficiarão disso, tornando a carne bovina brasileira um produto, saudável, seguro e social e ambientalmente corretos. 


\section{REFERÊNCIAS}

ASSO CIAÇÃO BRASILEIRA DAS INDÚSTRIAS EXPORTADORAS DE CARNE - ABIEC. Evolução da exportação de carne pelo Brasil, 2007. Disponível em: <http:/ / www.abiec.com.br/ estatisticas relatorios.asp>. Acesso em: 10 out. 2007.

BRASIL ESCO LA »HISTÓ RIA D O BRASIL » BRASIL REG IO NAL. Charqueadas. D isponível em: <http:// www.brasilescola.com/ historiab/ charqueadas.htm>. Acesso em: 12 dez. 2007.

MINISTÉRIO DA AGRICULTURA, PECUÁRIA E ABASTECIMENTO - MAPA. Cenário internacional para a pecuária brasileira, 2007. Disponível em: <www.agricultura.gov.br>. A cesso em: 10 nov. 2007.

MUSTEFAGA, P. S. Princípios da rastreabilidade na produção animal. Nota Técnica n. 5 - CNA. Brasília, 3 abr. 2006. Disponível em: <www.cna.org.br/ site/ down_anexo.php?q=E15_14776NT+5.pdf>. acesso em: 12 dez. 2007.

PROGRAMA NACIONAL DE CONTROLE E ERRADICACC̃O DA BRUCELOSE E DA TUBERCULOSE ANIMAL - PNCEBT. D isponível em: <http:/ / www.agricultura.gov.br>. Acesso em 15 out. 2007.

SCOT CO NSULTO RIA. Pecuária de Corte, 2007. D isponível em: <www.scotconsultoria.com.br>. Acesso em: 05 nov. 2007.

VILA, F.; YASSU, F.; FRANCO, M. D rible no arrocho. DBO, ano 26, n. 324, p. 48-58, 2007.

Recebido: 06/ 05/ 2008

Received: 05/ 06/2008

Aprovado: $14 / 05 / 2008$

A pproved: $05 / 14 / 2008$ 